\title{
A Systematic Review on Using Literature for the Young Learners in an EFL Classroom
}

\author{
Badria A. Al-hajji ${ }^{1} \&$ Khaled M. Shuqair ${ }^{1}$ \\ ${ }^{1}$ English Department, College of Basic Education, Kuwait \\ Correspondence: Khaled M. Shuqair, Assistant Professor, English Department, College of Basic Education, \\ Kuwait. E-mail: kmshuqair@gmail.com
}

Received: May 12, 2014 Accepted: June 14, 2014 Online Published: July 15, 2014

doi:10.5539/elt.v7n8p75 URL: http://dx.doi.org/10.5539/elt.v7n8p75

\begin{abstract}
This study has objectives that are exploratory and analytical in nature. It focuses on the use of relevant information with regard to the use of literature in EFL classrooms that is available for an analysis in order to draw conclusions and make useful recommendations. The study is, therefore, conducted as library research using the method of systematic reviews. The rationale for choosing this method is that there is an overwhelming quantity of research, which presents diverse views of the use of literature-based teaching strategies in EFL classrooms. The best way to extract information that can be synthesised for knowledge is to adopt a systematic approach using the most comprehensive and reliable library sources available
\end{abstract}

Keywords: literature in EFL classrooms, English in EFL classrooms, effectiveness of literature-based teaching strategies

\section{Introduction}

\subsection{Background}

This research attempts to highlight the benefits of using literature-based teaching strategies for young learners in EFL classrooms. This investigation has objectives that are exploratory and analytical in nature. It will, therefore, focus on the use of relevant information with regard to the use of literature in EFL classrooms that is available for an analysis in order to draw conclusions and make useful recommendations. The study will therefore be conducted as library research using the method of systematic reviews. The rationale for choosing this method is that there is an overwhelming quantity of research, which presents diverse views of the use of literature-based teaching strategies in EFL classrooms. The best way to extract information that can be synthesised for knowledge is to adopt a systematic approach using the most comprehensive and reliable library sources available. Antman et al. (1992) pointed out the failures of traditional reviews in such circumstances and stated that a rigorous systematic approach is the best way forward.

\subsection{Research Objectives}

This study attempts to explore the use of literature in teaching English in EFL classrooms. This will be achieved through a systematic review of current research studies on the use of literature in EFL classrooms as an English teaching strategy in non-English speaking nations.

Specifically, the study aims to identify the following:

1) Current literature-based teaching strategies for English

2) Current trends on the use of literature in EFL classrooms

3) Effectiveness of the use of literature-based teaching strategies in EFL classrooms

\subsection{Significance of the Study}

This study is grounded in the understanding that teaching English in EFL classrooms is now becoming an international trend, which must be addressed by all globally competitive, non-English speaking nations. Unfortunately, motivating students to learn English is becoming a major concern. One Vietnamese study has shown that young learners would easily get confused or frustrated in learning English when difficult words are not explained by the teacher or when grammar guidelines and style-points are missing (Pham, 2000). In a similar 
study conducted in Beirut, Lebanon, it appeared that the use of uninteresting materials, the lack of any new learning experience, and the ambiguous link between their current English courses and their future careers were among the major factors that hinder their motivation to learn English. The same study had also shown that when teachers use unique strategies that are tailor-fitted to the needs and personalities of their learners, students learn to adopt more positive attitudes towards learning the language (Bahous, 2011). Ultimately, the challenge is in initiating and maintaining young learners' interest in learning English, and studies have shown that one of the best ways to achieving such a goal is through extensive reading (Brown, 2000). Extensive reading helps young learners gain more interest and increases their confidence and fluency in speaking and writing in English. Such cultivates the habit of reading in a foreign (English) language. However, the problem in some countries is the lack of unified knowledge on how to motivate students to read more English works. In the Japanese study conducted by Waring and Takahashi (2000), English classes are mostly dedicated to translating the work into Japanese rather than understanding its deeper meaning, as is being done in many literary works. The authors further argue that while general translation enhances comprehension, it reduces English into a purely academic exercise and takes away from the learners the excitement and the willingness to learn the language.

As we have seen, there exists an extensive amount of knowledge base available that focus on the use of literature in EFL classrooms. However, every study proposes their own methods of using literature in teaching English in EFL classrooms. The present study aims at extracting information that can be synthesised for knowledge by adopting a systematic approach using the most comprehensive and reliable library sources available

\subsection{Scope and Limitations}

The success of a systematic review depends primarily on the criteria for selecting materials to be included in the studies, because the conclusions and recommendations will be drawn from the materials obtained in the list of articles reviewed. Thus, a systematic search strategy, being a fundamental requirement of this method, is crucial and will assist in providing valid and reliable answers to the research questions. The scope of the research is the first strategy to consider. This study attempts to describe the use of literature in teaching English in EFL classrooms. It will be concerned only with the use of any literature-based teaching strategy for teaching English to young learners in EFL classrooms. Thus the study will exclude all other English-teaching methods and those taught in English-speaking nations such as the UK, US, Australia, etc.

Secondly, the systematic review will include only relevant papers, which have been submitted from 2000 up to the present time and will exclude older materials. The search for materials will be limited to data from journals kept in two databases namely, PubMed and Sage Journals.

\subsection{Data Synthesis Method}

All the studies gathered during the systematic review are classified according to the type of teaching/learning strategy in order to create a picture of the value of literature-based teaching strategies for young learners in EFL classrooms. This will be followed by the researchers collating all the results for each type of literature-based strategy; that is contextualized storytelling, picture book reading, etc. in order to create an over-all picture of the value of literature in EFL classrooms. The information obtained will then be analysed based on the following subheadings: current literature-based teaching strategies for English; current trends on the use of literature in EFL classrooms; effectiveness of the use of literature-based teaching strategies in EFL classrooms; and education reform initiatives needed by countries wherein English is considered as an EFL to maximize learning.

\section{Discussion}

\subsection{The Use of Literature in an EFL Classroom}

Throughout history, it is evident that teaching children about the basics of English is one of the main objectives of education. This is important: especially when we consider the fact that English is the primary medium of teaching across the globe. The vast amounts of available literature on this topic are evidence of the extensive research interest on every aspect of teaching, learning, understanding and speaking English. Indeed, by the turn of the millennia, more and more countries are pushed to include English in their respective scholastic curricula, especially with the increasing globalization of English. Such a trend had subsequently forced non-English speaking countries to respond to this need by forging English-speaking environments, which will hopefully make it easy for them to interact in English speaking countries (Graddol, 2006).

However, for non-English speaking nations, teaching children how to comprehend and speak in English can be a difficult process. This means that learning English has to begin at a young age. In Taiwan, for example, English was incorporated in their school curricula in 2001, and had to be integrated into the learning modules beginning in the third grade (Taiwan Ministry of Education, 2001). Similarly, Korea had to make the same arrangement in 
their own curriculum and was bombarded with several critical issues in teaching English (O'donnel, 2005). This ultimately prompted the search for more effective English-teaching methods for EFL classrooms.

As such, even as far back as in the late $20^{\text {th }}$ century, researchers have already identified several difficulties in teaching English to non-English speaking young learners. Evidence shows that the general lack of motivation is at the core of young learners' reading difficulties in an EFL classroom. In Korea, Clark (2000) singled-out the lack of motivation as a major challenge in teaching English among young Korean learners. Kang (2000), further, found that among $2349^{\text {th }}$-graders in Korea, English remained a purely academic exercise, where students learn no more than what is needed to pass the subject. This negatively affects their ability to comprehend what they read. It is for this reason that researchers have been on the hunt for the most effective methods of teaching young learners how to read and speak English in an EFL classroom (Chang, 2006).

Over the years, experts have designed teaching strategies to help young learners learn in an EFL classroom. In Korea, a system called "CALL" or "Computer-Aided/Assisted Language Learning," which was used to help young learners in mastering English (O’Donnel, 2005). Another Asian study investigated the use of drama activities in enhancing learning in EFL classrooms. It was further found that using drama helps motivate students and creates a learning environment that is filled with fun and entertainment (Zyoud, 2010). However, among the many teaching strategies created, by far the most popular technique is reading English from all types of literature. Brown (2000) posited that extensive reading helps young learners gain more interest and increase their confidence and fluency in speaking and writing in English. Such a technique cultivates the habit of reading in a foreign (English) language. Cary (1998) proposed the use of "contextualized storytelling" on the use of literature for EFL classrooms. This method is unlike the traditional means of telling stories in that it highlights the verbal or vocal performance of the readers or storytellers. In this case, the author posits that this "multi-sensory" approach encourages learners to listen and learn more about the English language. Later, in 2005, another study highlighted a skills-based approach in the use of literature for EFL classrooms. In his study, the author concluded that phonetic awareness is critical in helping children learn English (Anderson, 2005). Then in 2006, Hsieh found that combining physical response with storytelling helps in motivating young learners to learn English.

Literature as a study subject has been used in most countries in the world at the tertiary and secondary levels, but it has been recently introduced and given as much attention in the EFL classroom like the latter levels. In the early 1980s some interest was developed among EFL teachers to utilize literature in their classrooms. Before using any method to use literature in the EFL classroom, one must understand what literature is. According to the Macmillan English dictionary, literature is defined as "stories, poems, and plays, especially those that are considered to have value as art and not just entertainment". But a more general definition views literature as products that show and explain the society's different aspects. They are also products that document cultures and give an in depth comprehension of a society (Akyel \& Yalcin, 1993, p. 176). Other scholars refer to literature as the interpretation of the reader in that it does not have a particular quality or order (Kilickaya, 2004, pp. 4-5).

\subsection{Pros and Cons of the Use of Literature in an EFL Classroom}

Several reasons have been put forward as to why literature should be involved in the EFL classroom. Some of these reasons are: Literature material is always authentic in that, when the learners are exposed to unmodified language in the EFL classroom they acquire skills which can be used outside the classroom. Second, interaction is encouraged by literature in that literature has several meanings and can be used to develop discussions in the sharing of opinions and feelings. Third, the awareness of language is expanded by the use of literature as learners deal with language that is not standard, which helps them understand norms associated with language use (Liaw, 2001, p. 37). Fourth, literature can be really motivating due to the high status it holds in many countries and cultures. Also, last but not least literature is more interesting than the usual course textbooks, thus making it easier for learners in the EFL classroom.

However, despite the massive success received in using literature to teach English in EFL classrooms, there is still an existing debate on its benefits. In his study, Al Mullah (2006) later contradicted the use of literature in EFL classrooms because it frustrated students, especially when they knew very little words. Hence, students later read very slowly and ultimately were discouraged to learn the language. Indeed, massive amounts of literature are available on the use of literature in EFL classrooms. However, the contradicting outcomes obscure its benefits and lead one to question whether using literature is indeed beneficial for young learners in non-English speaking countries.

\subsection{Current Literature-Based Teaching Models}

There are several models put forward in using literature for teaching EFL students. How the teacher uses the literature texts is highly dependent on the preferred model for teaching. These models include: The cultural model, 
the language model and the personal growth model. These models are discussed in detail in the following paragraphs.

The cultural model describes literature as products in that it is used as a source of information for a specific culture. It is the model that is usually used by teachers in EFL classrooms but usually in the higher level institutions. This model looks into the political, historical and social backgrounds of a literary text, genres and literary movements. The downside to this model is that it is centred on the teacher.

The language model main focus is on the learner. As the students in the EFL classroom go through a literary text, they are to give maximum attention to the particular way language is utilized. Due to this, they increase their understanding on the meaning and improve their overall awareness of the English language. The teacher in the EFL classroom can use this model to specifically focus on the overall vocabulary and grammar or utilize stylistic analysis. Stylistic analysis entails the detailed study of the used linguistic features in the literary text to assist the learners to come into understandable conclusive interpretations of the literary text, which assists students understand literature well. The language model is best suited for young learners in the EFL classroom.

The personal growth model takes into consideration the step by step approach and, like the language model, it is also student centred. This approach encourages the students to bring out their own personal experiences, opinions and feelings. Its main focus is to create an interaction between the reader and the text in English, assisting the learner to remember the language easily. The students are encouraged to see the literary text as their own. It also takes into consideration the great potential and effect literature can have on individuals and thus tries to apply that in the EFL classroom setup for the young learners.

\subsection{Effective Literature-Based Teaching Strategies}

According to Savvidou (2004), the utilization of storybooks is the most effective way of teaching learners in an EFL classroom. This is due to the fact that the stories act as motivators to young learners and are at par with their cognitive level. The stories contained in storybooks serve as authentic in their context because through them young learners can be introduced to basic language structures and vocabulary. Moreover, with the aid of the stories young learners in an EFL class gain literacy skills which assist them when learning how to read and write.

From the initial stages of learning a foreign language the experiences of the young learners have a huge impact on the future of the children learning experience. It is important that the experiences be confidence-building, enjoyable, and successful for the student. This can be achieved through goals in the sphere of linguistic competence and goals in the sphere of affective domain.

With regard to linguistic competence, it is imperative that due to the fact that a child learns how to communicate orally takes place first before the child can learn how to read and write. Therefore, the appropriate EFL schedule for the young children should follow the chronological steps of the natural process of learning the first language. These steps include: the basic aural/oral competence growth along with the emerging skills in literacy to writing and reading, utilizing the literacy skills obtained at the oral or aural period. While the learners are at the writing and reading stage, they will begin creating relationships between the literacy skills obtained during the oral and aural phase to the sentences, word and letters at the reading and writing phase. The oral competencies serve to create a strong base to the success of the reading and writing phase. Therefore, the initials phase in the foreign language instruction for children should be establishing and gaining lexical knowledge and skills for oral communication, at the same time developing aural phonemic awareness and the general emerging skills of literacy through the use of storybooks.

In the affective domain the teacher of the young learners should strive to create a positive first encounter with English as a foreign language, develop an environment in the classroom that is supportive to the EFL young learners, build up the learners confidence in the knowledge they posses and their ability to comprehend and utilize the foreign language, allowing young learners to practice the language in an environment that is not threatening, and provide motivation to the learners for learning the language through the utilization of interesting, colourful, and attractive visuals and materials.

Authentic literature is required to instruct children in the initial stages of learning English as a foreign language as it assists them in learning and developing the languages literary skills. For an effective development of the young learner's social, communicative and cognitive skills an approach that is story based proves to be quite effective and advantageous. It also takes into consideration the young child's affective needs and interests. Ghosn (2002, pp. 172-179) gives four important reasons for utilizing authentic children literature with young students in an EFL classroom. First, stories have a meaningful and motivating context for utilization in the process of learning language. Due to the fact that normally children are interested in stories, they strive to get the meaning of the story 
and thus are encouraged to develop understanding in the sense of looking up the meaning, guessing the context of the story and predicting. Second, stories play a huge role in the learning of language, in that stories offer a wide source of contextualized texts for the enrichment of language and the acquisition of vocabulary and reinforcement, and they also help in the development of oral language by offering a context that is authentic for interaction verbally, discussion, role play and dialogue. Also, stories encourage communication naturally through listening and giving responses to questions, the sharing of ideas and the expression of dislikes and likes. Third, authentic children's literature encourages the development of thinking and literacy skills in the young learners in an EFL classroom in that the literature can lead to thinking in the high order in the course of the question and answer exchanges, reflection and personal responses. This facilitates reading and comprehension of English as a foreign language. Lastly, authentic children's literature can act as an agent of change in that it facilitates interpersonal development in children, thus improving the language comprehension.

The teacher should strive to use content that is fairly familiar to the young learners in an EFL classroom. The language structures, topics and vocabulary which are the basis for the EFL program should be derived from the learner's field of experiences such as family, school, home and animals, among others. The selection of topics that are familiar to the children helps them to relate easily to the learning experience of the language.

For the teacher to be all inclusive of all the different styles of learning in an EFL classroom of young learners, various teaching approaches should be used to retain the consistency of the learner's interest at its peak. In addition the teaching approaches and the activities carried out should be fitting to the learner's level of cognition and also take into consideration the child's affective needs. The approaches utilized should allow the young learners to carry out the class assignments collectively, such as group responses and reading out loud alongside the teacher. The approaches should also allow small groups interaction for exchanging ideas, negotiating and developing group results. Another approach of teaching allows the young learners work in pairs to enable the young learners to be involved and engaged in oral interactions and dialogues which will go a long way in developing their language and literacy skills. Lastly the teaching approaches should allow for individual work which will enable the young learner in the EFL classroom give some thought into the English language, practice, internalize and also try to apply the skills learnt in class in the real world.

In light of the activities the teacher decides to use for the development of language skills in the young learner, they should offer several sources of language usage and opportunities for emphasis, internalization, and the utilization of the language. The activities should also be multi sensory in that, they should take care of the different needs and learning preferences of the young learners. These activities include: arts and craft, singing, listening to stories, solving puzzles, playing games, acting out and drama among other many activities that can be incorporated in an EFL classroom.

\section{Conclusion}

This study shows that using literature for young learners in an EFL classroom can be a fun and effective way of teaching English as a foreign language. Young learners are usually excited as literature helps them forget about their anxieties of learning English as a new language. The story teller Shurman Dvora says, "The best way to teach is not to impose teaching, but to allow the listener to become so involved in hearing a story that his 'defences' are no longer active." It is from the children's sense of excitement, emotional involvement and enjoyment that learning a new language stems, and thus the utilisation of literature in an EFL classroom does magic in helping the young learners learn English as a foreign language.

To summarize, this study shows that for the teacher to use literature effectively for young learners in an EFL classroom, he/she has to be all inclusive of all the different styles of learning in an EFL classroom of young learners using literature. The various teaching approaches should be used to retain the consistency of the learner's interest at its peak. In addition, the literature-based teaching approaches and the activities carried out should be fitting to the learner's level of cognition and take into consideration the child's affective needs. The approaches utilized should allow the young learners to carry out the class assignments collectively, such as group responses and reading out loud of literature alongside the teacher. The approaches should also allow small groups interaction for exchanging ideas, negotiating and developing group results. The teaching approaches of utilising literature for the young learners in an EFL set up should allow for individual work which will enable the young learner in the EFL classroom give some thought into the English language, practice, internalize and try to apply the skills learnt in class in real contexts.

\section{References}

Akyel, A., \& Yalçin, E. (1990). Literature in the EFL class: A study of goal-achievement incongruence. ELT Journal, 44(3), 174-180. 
Al Mulla, K. (2007). Developing young learners' reading skills in an EFL classroom. Retrieved December 22, 2013, from http://marifa.hct.ac.ae/files/2011/07/

Anderson, S. R. (2005). Aspects of the Theory of Clitics. Oxford: Oxford University Press.

Antman, E. M. et al. (1992). A comparison of results of meta-analyses of randomized control trials and recommendations of clinical experts: Treatments for myocardial infarction. JAMA, 268, 240-248.

Bahous, R. (2011). Motivating students in the EFL classroom: A case study of perspectives. English Language Teaching, 4(3), 33-43.

Brown, R. (2000). Cultural continuity and ELT teacher training. ELT Journal, 54(3), 227-234.

Cary, S. (2000). Working with second language learners: Answers to teachers' top ten questions (Vol. 10). Heinemann.

Chang, A. C. S., \& Read, J. (2006). The effects of listening support on the listening performance of EFL learners. TESOL Quarterly, 40(2), 375-397.

Clark, J. C. D. (2000). English society, 1660-1832: Religion, ideology and politics during the ancien regime. Cambridge: Cambridge University Press.

Ghosn, I.-K. (2002). Four good reasons to use literature in primary ELT. ELT Journal, 56(2), 172-179.

Graddol, D. (2006). English next (Vol. 62). London: British Council.

Kang, D.-H. (2000). Motivation and Foreign Language Learning in Korean EFL Context. Retrieved January 2, 2014, from http://files.eric.ed.gov/fulltext

Kilickaya, F. (2004). Authentic materials and cultural content in EFL classrooms. The Internet TESL Journal, 10(7), 1-6.

Liaw, M. L. (2001). Exploring literary responses in an EFL classroom. Foreign Language Annals, 34(1), 35-44.

O'Donnell, K. (2005). Japanese secondary English teachers: Negotiation of educational roles in the face of curricular reform. Language, Culture and Curriculum, 18(3), 300-315.

Pham, H. H. (2000). Traditional versus modern methods. Teacher's Edition, 2, $20-24$.

Savvidou, C. (2004). An integrated approach to teaching literature in the EFL classroom. The Internet TESL Journal, 10(12).

Taiwan Ministry of Education. (2001). Retrieved April 30, 2014, from http://english.moe.gov.tw/

Van, T. T. M. (2009). The relevance of literary analysis to teaching literature in the EFL classroom. English Teaching Forum, 47(3), 2. US Department of State. Bureau of Educational and Cultural Affairs, Office of English Language Programs, Washington D.C.

Waring, R., \& Takahashi, S. (2000). The Why and How of Using Graded Readers. Tokyo: Oxford.

Zyoud, M. (2010). Using drama activities and techniques to foster teaching English as a foreign language: A theoretical perspective. Retrieved January 30, 2014, from http://www.qou.edu/english/conferences/ firstNationalConference

\section{Copyrights}

Copyright for this article is retained by the author(s), with first publication rights granted to the journal.

This is an open-access article distributed under the terms and conditions of the Creative Commons Attribution license (http://creativecommons.org/licenses/by/3.0/). 